\title{
An in situ erosive study of soft drinks modified with xanthan gum
}

\author{
Modification of soft drinks with xanthan gum to minimise erosion: a study in situ \\ N. X. West, J. A. Hughes, D. Parker, L. J. Weaver, M. Moohan, J. De'Ath and M. Addy \\ Br Dent J 2004; 196: 478-481
}

\section{Objective}

To compare the erosive effect of a new blackcurrant/calcium drink with xanthan gum, on enamel in situ, with a low erosive product, a conventional fruit beverage and water.

\section{Design}

The study was single centre, randomised, single blind, 4 treatment crossover design.

\section{Setting}

This study, conducted in 2000, employed volunteers working at the Bristol Dental Hospital, UK.

Subjects, materials and methods

16 subjects ( $\geq 18$ years) wore two enamel samples in a removable acrylic appliance. The drinks tested were (A) New blackcurrant/ calcium/gum drink (test product), (B) Original blackcurrant/calcium drink, (C) Conventional blackcurrant drink (positive control) and (D) Water (negative control), for 15 day study periods. Drinking was supervised, with $250 \mathrm{ml}$ imbibed four times/day between $9.00 \mathrm{am}-5.00 \mathrm{pm}$. Profile measurements of specimens were made at baseline, 5, 10 and 15 days.

\section{Main outcome measures}

Paired $t$-tests compared erosion by surfometry with selected pairs of formulations.

\section{Results}

Of 16 screened subjects ( 3 male, 13 female), mean age 34.2 years, 1 subject failed to complete the study. A caused significantly less enamel loss than $\mathrm{C}$, with no statistically significant differences from $B$ at any time points measured. Of 43 treatment emergent adverse events, none were considered related to the study formulations.

\section{Conclusions}

A retained low erosive properties similar to B, with additional benefits of taste flexibility and beverage stability.

\section{IN BRIEF}

- Peer reviewed publications demonstrate the low erosive properties of a blackcurrant/ calcium drink. Further development of this beverage, by incorporation of xanthan gum, allows the beverage to increase in acidity to optimise variables such as consumer acceptance and stability, whilst retaining its low erosive potential to enamel.

- The drinks tested, a new blackcurrant/calcium/gum drink (test product), and the original blackcurrant/calcium drink were both shown to be significantly less erosive to enamel than a conventional juice drink.

- These low erosive beverages may be a valuable alternative to other acidic soft drinks for those individuals susceptible to erosion.

\section{COMMENT}

We frequently advise that children and adolescents reduce their intake of acidic drinks, ideally drinking only milk or water. However, increasing sales of soft drinks indicate that this advice is being ignored; its realism can also legitimately be questioned. Reduction in erosive potential of soft drinks is, therefore, a practical and responsible way of minimising the risk of tooth wear in susceptible individuals.

A still soft drink with low erosive potential (Ribena ToothKind ${ }^{T M}$ SmithKline Beecham, Coleford, UK) was first marketed in 1998, its development being documented in a series of papers. ${ }^{1-3}$ Though it was recognised that the taste and stability of the marketed product could be enhanced, it was crucial that any change in formulation did not adversely affect its low erosive properties.

In this study, validated in situ methodology was used to compare the erosive effect of a new formulation blackcurrant drink containing calcium and xanthan gum with the marketed blackcurrant/calcium product; a conventional 'no added sugar' blackcurrant drink and water acted as the positive and negative controls. It is encouraging to note that it was possible to achieve the goals of enhanced consumer acceptability and shelf life without detriment to erosive potential. Indeed, the new formulation consistently produced less erosion than did blackcurrant Ribena ToothKind ${ }^{T M}$, though the difference between the two products did not reach statistical significance.

Perhaps the most valuable observation to be made from reading this study is that both the new formulation blackcurrant drink and blackcurrant Ribena ToothKind ${ }^{\mathrm{TM}}$ were minimally erosive to enamel when compared with a conventional blackcurrant drink. This validates the findings of the original series of developmental studies referred to above.

\section{Dr Lindsay Hunter}

Clinical Senior Lecturer in Paediatric Dentistry, University of Wales College of Medicine

doi:10.1038/sj.bdj.4811186

1. Hughes J A, West NX, Parker D M, Newcombe R G, Addy M. Development and evaluation of a low erosive blackcurrant juice drink in vitro and in situ 1. Comparison with orange juice. J Dent 1999; 27: 285-289.

2. West N X, Hughes J A, Parker D M, Newcombe R G, Addy M. Development and evaluation of a low erosive blackcurrant juice drink 2. Comparison with a conventional blackcurrant juice drink and orange juice. J Dent 1999: 27: 341-344.

3. Hughes J A, West N X, Parker D M, Newcombe R G, Addy M. Development and evaluation of a low erosive blackcurrant juice drink 3. Final drink and concentrate formulae comparisons in situand overview of the concept. J Dent 1999; 27: 345-350. 